\title{
SUPERIOR SOMATIC PAIN RELIEF AND IMPROVED VISCERAL PAIN CONTROL IS ACHIEVED USING PRE-EMPTIVE ANALGESIA FOR LAPAROSCOPIC CHOLECYSTECTOMY: A RANDOMIZED CONTROLLED TRIAL
}

\author{
Koh PS ${ }^{1}$, Cha KH ${ }^{2}$, Lucy $C^{3}$, Rampal $S^{4}$, Yoong BK ${ }^{1}$ \\ 1 Department of Surgery, Faculty of Medicine, University of Malaya, Kuala Lumpur \\ 2 Sime Darby Medical Centre, Subang Jaya \\ 3 Department of Anaesthesiology, Faculty of Medicine, University of Malaya, Kuala Lumpur \\ 4 Department of Social and Preventive Medicine, Faculty of Medicine, University of Malaya, Kuala Lumpur
}

\section{Correspondence:}

Dr. Peng Soon Koh,

Department of Surgery, Faculty of Medicine,

University Malaya, Lembah Pantai, Kuala Lumpur 50603, Malaysia.

E mail: kohps2000@yahoo.com

Telephone: +60-379492070 Fax: +60-379586360

\begin{abstract}
BACKGROUND:

Laparoscopic cholecystectomy, although is less invasive than open surgery, is not completely pain free. The use of local anaesthesia to relieve pain following this procedure is a common practice. However, it remains debatable whether a pre- or post-operative drug administration is more effective. Here, we investigated the role of preemptive local anaesthetic infiltration given pre- or post-incisional, in relieving the pain during laparoscopic surgery.
\end{abstract}

\section{METHODOLOGY:}

A randomized controlled trial was conducted with 96 patients receiving 0.5\% Bupivacaine 100mg. Group A $(n=48)$ received post-incisional skin infiltration whilst Group B $(n=48)$ received pre-incisional infiltration. Incisional (somatic) and intra-abdominal (visceral) pain was assessed using Visual Analog Scale (VAS) at day 0 , day 1 and day 7 post-operative days.

\section{RESULT:}

Baseline characteristics between the two groups were similar. Incisional pain was lower in Group B as compared to Group $A$ at day $0(P=0.03)$ and day $1(P<0.01)$. Intra-abdominal pain was also lower in Group $B$ at day 0 and day $1(P=0.04)$. VAS score was similar at day 7 although analgesia requirement is higher in Group $\mathrm{A}(P>0.05)$.

\section{CONCLUSION:}

Administration of pre-incisional local anaesthesia offers better pre-emptive pain relief measure than postincisional administration by reducing somatic and visceral pain in laparoscopic gall bladder surgery.

Keywords: laparoscopic cholecystectomy, preemptive analgesia, pain, ethnicity, local anaesthesia

\section{Introduction}

Laparoscopic cholecystectomy is the "gold" standard for gall bladder surgeries today (1). It is well established that minimally invasive surgery is associated with less morbidity as compared to open procedures. In addition, it has been shown that patients undergoing laparoscopic procedures experience less post-operative pain, reduced analgesia consumption and reduced length of hospital stay. However, the procedure is not entirely pain-free as some amount of pain is still associated with laparoscopic procedures $(2,3)$.

At present, pain management in laparoscopic cholecystectomy has taken a multi-modality approach. The concept of giving pre-emptive analgesia in surgical operations has been widely studied and its use in 
laparoscopic procedure such as cholecystectomy is well recognized in various studies (4). It is a common practice for pre-emptive analgesia technique that local anaesthesia to be administered as a post-incisional infiltration. However, how this compares to a pre-incisional local anaesthesia remains, as it is not well studied.

Hence, we compared the pain outcome in patients undergoing laparoscopic cholecystectomy receiving preemptive or pre-incisional local anaesthetic infiltration with those receiving a post infiltration local anaesthetic infiltration. We also aim to determine whether pain in patients undergoing laparoscopic cholecystectomy receiving local anaesthetic infiltration is influenced by their demographic profiles such as ethnicity. This study will provide a new perspective for the use of pre-incisional local anaesthesia infiltration in laparoscopic surgeries conducted in University Malaya Medical Centre.

\section{Methodology}

\section{Study period, design and sample size}

A randomized controlled trial was conducted in the University Malaya Medical Centre (UMMC) for the period of August 2006 to June 2008. This study has been approved by the Medical Ethics Committee (MEC) of University Malaya Medical Center [Ethics committee/IRB reference number: 547]. The patients were randomized into two groups: Group A receiving post-incisional local anaesthetic infiltration and Group B receiving preemptive or pre-incisional local anaesthetic infiltration. All patients enrolled in the study had given their written and informed consent prior to surgery.

During the study period, 96 patients from a total of 103 patients undergoing elective laparoscopic cholecystectomy were recruited for the study. The remaining seven were excluded as these patients were converted to open cholecystectomy during laparoscopic surgery. Except for three patients who had gall bladder polyps, all patients undergoing elective laparoscopic cholecystectomy had underlying cholelithiasis which, is a common symptom for biliary colic. In addition, these patients had previous history of cholecystitis or pancreatitis, which were treated conservatively prior to surgery.

\section{Inclusion and exclusion criteria}

Patients between the ages of 18 to 60, who were undergoing elective laparoscopic cholecystectomy with an American Society of Anesthesiologists (ASA) I and II were included in the study. Patients with an ASA of III, emergency laparoscopic cholecystectomy or major perioperative complication were excluded from this study. Patients were admitted one day prior to surgery and were discharged home on the first or second post-operative day.

\section{Anaesthesia}

A standard anaesthesia induction was performed using intravenous propofol (2-3mg/kg), fentanyl (1-2mcg/kg) and muscle relaxant atracurium $(0.5 \mathrm{mg} / \mathrm{kg})$ or rocuronium $(0.6 \mathrm{mg} / \mathrm{kg})$. Anaesthesia was maintained throughout surgery through the inhalational of sevoflurane and intravenous morphine $(0.1-0.2 \mathrm{mg} / \mathrm{kg})$. Patients were mechanically ventilated with $\mathrm{CO}_{2}$ at $35-40 \mathrm{mmHg}$.

Patients received subcutaneous or oral tramadol $50 \mathrm{mg}$ thrice a day post-operatively and additional tramadol was given in the event of breakthrough pain. Other forms of analgesia were also given to those who experienced nausea and vomiting due to tramadol intolerance. Analgesic requirement were measured both at the first 24 hours post-surgery before discharge and at the end of 7 days post-surgery. The amount of morphine escaped was noted during the immediate post-surgery period.

\section{Surgical technique and local anaesthetic infiltration}

The operative procedure was performed using the Hassan or open technique for the initial port placement, with a standard four port technique using two $10 \mathrm{~mm}$ ports placed in the epigastrium and peri-umbilical region and two $5 \mathrm{~mm}$ ports placed at the subcostal area at the mid-clavicular and anterior axillary line. The abdomen was insufflated with the abdominal pressure maintained at $12-14 \mathrm{mmHg}$.

We used 0.5\% Bupivacaine $100 \mathrm{mg}(20 \mathrm{ml})$ as our choice of local anaesthetic agent (4). About $5 \mathrm{ml}$ or $25 \mathrm{mg}$ of $0.5 \%$ Bupivacaine were infiltrated in each port site with attempts to infiltrate the local anaesthetic agent at the level of skin, fascia, peritoneum and periportally.

Group A received local anaesthetic infiltration at the end of surgery after removal of the laparoscopic ports which is the standard of practice in UMMC. Group B, received an infiltration of the local anaesthetic agent prior to laparoscopic port insertion. The local anaesthetic was given under direct vision for the first port insertion and the remaining ports are infiltrated under camera vision by first creating a bleb in the peritoneum and withdrawing it into the other levels and periportally.

\section{Pain assessment}

Patient's pain score was assessed post-operatively using the Visual Analogue Scale (VAS), which has a score of 0 to 10 . A score of 0 is attributed to being no pain and 10 being the worst imaginable pain. Assessment of pain is done by the Acute Pain Service (APS) $(5,6)$. Nurses were randomized to become independent assessor of patient's pain score with a standard questionnaire. Patients were thoroughly informed on how they would be asked on their pain outcome using the VAS score. 
Pain was assessed at two levels, namely:-

- Incisional (somatic) pain - pain is described to patient as a sharp, localized pain arising from the skin and incision site

- Intra-abdominal (visceral) pain - pain is described as a generalized, vague, dull aching, non-localized pain.

The above VAS score were assessed three times. The first assessment was done immediately after surgery or during the first six hours post-surgery when the patient regained full consciousness. The second assessment was performed 1 day post-surgery or prior to discharge. The final assessment was scored after 7-days post-surgery via a telephone call to patients with the same set of questionnaire repeated. Shoulder pain experienced by the patients was also enquired.

In addition, the amount of analgesia consumption or requirement was obtained from the medical record and telephone conversation. The requirement for an escape dose of morphine immediately after surgery was taken into account in patients who complained of severe pain with VAS $>3$. No patients were excluded from the study due to major complications resulted from the surgery.

Any major complication that arises post-operatively was also obtained from patients and patients were excluded from study if occurred. So far, we had no reports of major complication from patients enrolled in this study.

\section{Data and statistical analysis}

Demographic details such as gender, age, body mass index (BMI), ethnicity, length of operating time and prior endoscopic retrograde cholangiopancreatography (ERCP) were obtained. Both age and BMI was presented as mean \pm standard deviation (S.D.) and was analyzed using the Fisher Exact test. Length of operating time was presented as median (range) and was analyzed using the Mann-U Whitney test as data was presented as a continuous variable with a skewed distribution of the normal curve. The VAS score was determined for Day 0 (immediate postsurgery), Day 1 (the next day post-surgery) and Day 7 (one week post-surgery) as median (range). Statistical analysis was performed using the Mann-U Whitney test for the VAS score for both incisional and intra-abdominal pain respectively during the 3 occasions. Further analysis to determine the co-variates that may have affected the VAS score was performed. Here, Mann-U Whitney test was used for gender, $\mathrm{BMI}$, and ERCP, and Kruskal-Wallis test was used to determine the median differences of age and ethnicity in order to determine whether the above co-variables may affect the outcome of the VAS score.

The amount of escape doses of morphine required at the immediate post-operative period (Day 0) was assessed in both groups and presented as the amount of times required for this treatment. Statistical analysis was done using the Fischer Exact test. The analgesia requirement in both groups was also assessed from the amount of intake in the first 24 hours and at the end of one week, presented as median (range). Statistical analysis was done using the Mann-U Whitney test. A P value $<0.05$ indicates a statistically significant difference.

\section{Results}

\section{Demographic details and baseline characteristics}

A total of 103 patients were enrolled for the study from August 2006 to June 2008, out of which seven patients were excluded due to open conversion cholecystectomy. Hence the conversion surgical rate was determined at $6.8 \%$. The remaining 96 patients were equally randomized into two groups with 48 patients in each group.

Among the recruited subjects, 80 (83.3\%) were female and $16(16.7 \%)$ were male. These patients presented various gall bladder diseases ranging from cholelithiasis, previous history of cholecystitis, pancreatitis or choledocholithiasis, and gall bladder polyp. Ethnicity analysis showed that 46 (47.9\%) were Malay, 30 (31.3\%) were Chinese and, $17(17.7 \%)$ were Indian. The remaining 3 (3.1\%) were of other backgrounds and ethnicities. Majority of the patients (84 or $87.5 \%$ ) had no prior Endoscopic Retrograde Cholangiopancreatography (ERCP).

There was no significant difference between Group A and $B$ in relation to the gender, ethnicity, age, BMI, length of surgery and history of ERCP (Table 1). The mean age between Group A and Group B was 45.56 (S.D. \pm 10.82) and 46.08 (S.D. \pm 8.85 ) respectively whereas the mean BMI was 25.59 (S.D. \pm 5.34 ) and 26.87 (S.D. \pm 5.14) between Group A and Group B. Length of surgery was found to be 80.00 minutes (range 65.00-97.50) in Group A and 85.00 (range 60.00-105.00) minutes in Group B.

\section{Pain on Day 0 and escape dose with morphine}

Assigned APS nurses assessed patients VAS scores during the immediate post-surgery duration, i.e. when patient had regained consciousness and within 6 hours post-surgery period. The median VAS score for incisional pain was significantly higher in Group A was (3.5, range 0.0-5.8), when compared to those in Group B at $(0.5$, range $0.0-$ 5.0). The VAS score for incisional pain was not affected by gender, ethnicity, ERCP, age, and BMI.

The median VAS score for abdominal pain experienced by patients in Group A was 3.0 (range 0.0-7.0), which was higher than Group B at 1.5 (range 0.0-5.0); however, this was not statistically significant. Similarly, the VAS score for intra-abdominal pain was not affected by patients' gender, ethnicity, ERCP, age, and BMI.

Patients who complained of severe pain as reflected by a high pain score at immediate post-surgery and who received their required escape doses of morphine were also assessed. It was found that the amount was comparable in both groups without significant differences (Table 2). Pain score for incisional and intra-abdominal pain for both groups at Day 0 is summarized in the Table 3 . 
Table 1 - Baseline characteristic of control and intervention group.

\begin{tabular}{llll}
\hline & $\begin{array}{l}\text { Group A } \\
\mathrm{n}=48(\%)\end{array}$ & $\begin{array}{l}\text { Group B } \\
\mathrm{n}=48(\%)\end{array}$ & $P$-value \\
\hline $\begin{array}{l}\text { Gender } \\
\text { Male }\end{array}$ & $5(10.4)$ & $11(22.9)$ & 0.17 \\
Female & $43(89.6)$ & $37(77.1)$ & \\
$\begin{array}{l}\text { Ethnicity } \\
\text { Malay }\end{array}$ & $21(43.9)$ & $25(52.1)$ & 0.59 \\
$\begin{array}{l}\text { Chinese } \\
\text { Indian }\end{array}$ & $15(31.3)$ & $15(31.3)$ & \\
$\begin{array}{l}\text { Others } \\
\text { ERCP done }\end{array}$ & $1(2.0)$ & $6(12.5)$ & \\
$\begin{array}{l}\text { Yes } \\
\text { No }\end{array}$ & $4(8.3)$ & $2(4.1)$ & \\
& $44(91.7)$ & $8(16.7)$ & 0.36 \\
Age * & $45.56 \pm 10.82)$ & $46.08( \pm 8.3)$ & 0.80 \\
BMI * & $25.59( \pm 5.34)$ & $26.87( \pm 5.14)$ & 0.23 \\
$\begin{array}{l}\text { Length of } \\
\text { operation } \\
\text { (mins) \# }\end{array}$ & $80.00(65.00-97.50)$ & $85.00(60.00-105.00)$ & 0.97 \\
\hline
\end{tabular}

a. $P$-value in Fischer exact test unless otherwise stated

* values in mean \pm s.d. and independent t-test used for $p$-value

\# values in median (range) and Mann-U Whitney test used for $p$-value

Table 2 - Escape doses of morphine required immediate postoperative period

\begin{tabular}{llll}
\hline & $\begin{array}{l}\text { Group A } \\
\mathrm{n}=48\end{array}$ & $\begin{array}{l}\text { Group B } \\
\mathrm{n}=48\end{array}$ & $P$-value \\
\hline Escape dose required & 31 & 32 & 1.00 \\
Escape dose not required & 17 & 16 & \\
\hline
\end{tabular}

a. Fischer exact test used

Table 3 - Pain score at Day 0 and the influence of the covariates on VAS

\begin{tabular}{lllll}
\hline & Incisional pain & \multicolumn{2}{l}{ Intraabdominal pain } \\
& \multicolumn{1}{l}{ VAS score $P$-value } & VAS score $P$-value & \\
\hline Group A & $3.5(0.0-5.8)$ & 0.03 & $3.0(0.0-7.0)$ & 0.47 \\
Group B & $0.5(0.0-5.0)$ & $1.5(0.0-5.0)$ & \\
\hline
\end{tabular}

a. all values in median (range) and Mann-U Whitney test used for p-value unless otherwise stated.

* Kruskawallis test used for $P$-value

\section{Pain assessment and analgesia requirement on Day 1}

The median VAS score for incisional pain in the Group A patients was 5.0 (range 3.0-.6.0), which was higher than Group B at 1.0 (range 0.0-3.0) $(P<0.01)$ (Table 4). Again, the VAS score for incisional pain on Day1 was not influenced by gender, ethnicity, ERCP, age, and BMI.
We also observed that the median VAS score for intraabdominal pain in Group A was 5.0 (range 0.5-6.0), which was higher than Group B at 2.0 (range 0.0-5.0) $(P=0.04)$ (Table 4). Similarly, the VAS score for intra-abdominal pain was not influenced by gender, ERCP, and BMI.

Table 4 - Pain score at Day 1 and the influence of the covariates on VAS

\begin{tabular}{llll}
\hline & Incisional pain & \multicolumn{2}{l}{ Intraabdominal pain } \\
& VAS score $P$-value & \multicolumn{2}{l}{ VAS score $P$-value } \\
\hline Group A & $5.0(3.0-6.0)<0.01$ & $5.0(0.5-6.0)$ & 0.04 \\
Group B & $1.0(0.0-3.0)$ & $2.0(0.0-5.0)$ & \\
\hline
\end{tabular}

a. all values in median (range) and Mann-U Whitney test used unless otherwise stated.

* Kruskawallis test used

In addition, we examined the amount of times that analgesia was given to patients within the first operative day (Table 5). No significant difference was observed in the frequency of analgesic administration between the two groups.

Table 5 - Amount of times analgesia needed at Day 1 and the co-variates

\begin{tabular}{lll}
\hline & Amount of times analgesia needed & $p$-value \\
\hline Group A & $2.00(1.25-3.00)$ & 0.15 \\
Group B & $2.00(1.00-3.00)$ & \\
\hline
\end{tabular}

a. values in median (range) and Mann-U Whitney test used unless otherwise stated

* Kruskawallis test used

\section{Pain assessment and analgesia requirement on Day 7}

On the seventh post-operative day, a telephone call were made by the APS nurses to all patients enrolled in the study and the same question regarding their VAS score for incisional and intra-abdominal pain were repeated. Patients were also asked on the total amount of analgesia used at the end of one week. All patients did not encounter any significant post-operative complication when enquired.

We observed that the median VAS score for incisional and intra-abdominal pain on Day 7 were almost similar without significant difference in both groups (Table 6). The VAS score for incisional and intra-abdominal pain for either group was also not influenced by gender, ethnicity, ERCP, age, and BMI.

However, when reviewing the number of times that analgesia administered, we found a trend that Group A 
group required more at 5.0 (range 2.0-14.0) versus Group $B$ at 2.0 (range 1.3-3.0). although not statistically significant (Table 7).

Table 6-Pain score at Day 7 and the influence of the covariates on VAS

\begin{tabular}{lllll}
\hline & \multicolumn{1}{l}{ Incisional pain } & Intraabdominal pain \\
& \multicolumn{1}{l}{ VAS score p-value } & VAS score p-value & \\
\hline Group A & $2.0(0.0-3.0)$ & 0.80 & $0.0(0.0-2.0)$ & 0.74 \\
Group B & $0.0(0.0-2.0)$ & & $0.5(0.0-3.0)$ & \\
\hline
\end{tabular}

a. all values in median (range) and Mann-U Whitney test used unless otherwise stated.

* Kruskawallis test used

Table 7 - Amount of times analgesia needed at 1 week and the co-variates

\begin{tabular}{lll}
\hline & Amount of times analgesia needed & p-value \\
\hline Group A & $5.00(2.00-14.00)$ & 0.13 \\
Group B & $3.00(2.00-8.50)$ & \\
\hline
\end{tabular}

a. values in median (range) and Mann-U Whitney test used unless otherwise stated

* Kruskawallis test used

\section{Shoulder pain}

Our data shows that shoulder tip pain was not the main complaint of pain among our patients following laparoscopic cholecystectomy. Both groups showed similar complaints of shoulder tip pain following surgery $(P=0.82)$.

\section{Discussion}

Laparoscopic cholecystectomy is now considered a standard operating procedure for many gall bladder diseases in both developed and developing countries. Laparoscopic cholecystectomy can reduce morbidity, shorten hospital stay and reduce post-operative pain when compared to open cholecystectomy $(2,3,7)$. In our study, females represent the majority of patients with gall bladder diseases. In addition, cholelithiasis remains the most common gall bladder disease presented in this group. Our rate of conversion to open cholecystectomy was $6.8 \%$, which was almost similar to that reported in many other established centers around the world (8-10).

The ethnic distributions in our study population were equally distributed in both Group A and Group B, with no significant difference found between the two groups. There was also no difference between the VAS score from these ethnic groups. This is interesting to note, as it has been shown that patients of Indian ethnicity tend to have higher frequency and scoring of pain (11). We believe that pain assessed with an objective and quantitative assessment method such as the Visual Analog Scale (VAS), will not show any differences between these groups, as the expression of pain may differ from one individual to another. This may be due to their different cultural practices and upbringing, an aspect which was not taken into account in our study.

VAS score in assessment of pain is known to be the oldest, easiest and best validated form of measuring pain. (12). The role of using preemptive analgesia in surgical setting has been widely studied and applied in various disciplines by surgeons, obstetrician and gynaecologists (13). Its use ranges from simple administration of oral analgesic to local anaesthetic infiltration and, at times the use of more invasive procedures such as epidural or nerve blocks have been reported. The choice of technique or method aims to improve and reduce pain in patients undergoing any surgical procedures by administrating analgesia prior to surgery (14-16). In our study, we looked into patient pain outcome over a period of a week. This was done since Bisgaard et $a /$ had suggested that incisional or somatic pain seems to be the most common or dominant pain experienced by patients undergoing laparoscopic cholecystectomy during the first post-operative week (17). Although, laparoscopic cholecystectomy is known to reduce post-operative pain as compared to open cholecystectomy, it does not provide completely pain-free surgery. Pain following laparoscopic cholecystectomy can be considered multifactorial $(18,19)$. Bisgaard et al has suggested that pain in laparoscopic cholecystectomy is a combination of three different and clinically separate components, namely incisional pain (somatic pain), intra-abdominal pain (visceral pain) and shoulder pain (referred visceral pain) (20).

The idea for such preemptive use was first mooted by Woolf in 1983 when the idea of central sensitization was first introduced (21). Its application in the field of surgery was found to be most effective. It is worth to note that the perception of pain involves both peripheral and central nervous system. When there is a noxious stimulus such tissue injury in surgery, a cascade of pain pathways occur beginning at the site of injury where pain is relayed via the peripheral nerve to the spinal cord and then to the brain. Based on this knowledge, the use of preemptive analgesia administered prior to tissue injury, prevents central sensitization and reduces or limits the pain experienced by patients (22). In other words, central sensitization is reflected by the increase in pain perception following noxious stimuli and a decrease in threshold of the central nociceptive pathways after peripheral tissue injury or inflammation, which has been implicated in the development of hyperalgesia and maintenance of persistent pain following the noxious stimuli (23). Our findings also concur with many other studies regarding reduced post-operative pain among patients who had preemptive local anaesthetic infiltration at the incisional site. However, our study design was slightly different from others. In one study, the use of local anaesthetic infiltration at the incisional site was compared with placebo. Somehow this seems strange and the outcome would have been obvious since the administration of anaesthesia would undoubtedly provide better pain relief. 
In addition, the number of times and amount of analgesia was administered was not mentioned (24-26).

When comparing administration of local anaesthetic infiltration as a pre-incisional versus post incisional procedure, we found that it was a better option to give prior to port insertion. This also concur with findings by Uzunkoy et al $(27,28)$. Similar finding on the benefits of giving preemptive local anaesthetic infiltration for incision was also shown by Bisgaard et al and Lee et al $(17,29)$. Both studies examined administration of intraperitoneal local anaesthetic infiltration to provide more pain control and investigated the control of pain in the multimodality or multiregional aspect. Both studies also agreed that incisional or somatic pain was the most dominant pain experienced by patients during the early operative period. However, one study by Sarac et al showed that giving local anaesthetic infiltration provide better outcome in pain management when compared with placebo but further showed that pain score was lower when given post incisionally compared with preemptive administration (30).

Whilst shoulder pain remains the major complain for pain from gall bladder disease and thus, surgeries involving the gall bladder would yield similar complaints, our study does not appear to support this notion. It has been postulated that pain in the shoulder is the result of diaphragmatic stretching resulting in phrenic nerve neuropraxia (31). In order to reduce this, lower insufflation pressure and careful decompression may be the key to lowering pain. But not all studies appear to agree on this $(17,19,32,33)$. Perhaps the absence of shoulder pain in our study is not because of the local analgesia itself, but rather of the skill of the surgeons. However, this needs to be investigated further since we are not able to confirm or refute this hypothesis.

One limitation that we had observed in our study was insufficiency in post-operative pain management. This was not surprising since many studies including that of Rawal et al. had shown that there is a lack in the recognition of inadequate treatment of pain and that is continues to be a clinical problem in many hospitals worldwide (34). In our study, this is evident from Day 1 post operatively, when the control group had shown to have a higher pain score and yet analgesia consumption was almost similar to the intervention group. This suggests a limitation contributed by human factor. A survey by Bardiau et al found that knowledge of post-operative pain among nurses were lacking thus affecting skills in assessing and managing pain effectively among patients. When clinical guidelines or pain treatment protocols as well as the inception of the Acute Pain Service (APS) were applied, pain relief improved significantly (35).

Our study was not able to demonstrate the effectiveness of local analgesia in comparison to that of other modalities in relieving pain. It has been reported that other various preemptive analgesic techniques were also evaluated by other trials. Some trials have preemptively used dextromethorphan an NMDA (N-methyl-D-aspartate) receptor antagonist\}, NSAIDS, opiods, epidural, and multimodal analgesia with positive results in reducing pain among patients $(4,36,37)$. Other trials assessing the role of local anaesthetic given preemptively in the form of intraperitoneal instillation were also conducted where local anaesthetic agent were given intraperitoneally and compared with placebo or groups with instillation at the end of operation (31, 38-40). However, these techniques can only be conducted after extensive literature review and large-scale multi-centre trials since evidence of the use of these modalities does not appear to be supported by large number of evidence-based literatures $(4,17)$.

\section{Conclusion}

In conclusion, the use of preemptive pre-incisional local analgesia has been shown in our study to improve visceral and somatic pain more effectively than the administration of post-incisional local anaesthesia. In addition, shoulder tip pain in laparoscopic cholecystectomy was not form the main complaint among patients and that ethnicity does not influence the outcome of pain following surgery in many patients. Based on our findings, we can safely recommend that preemptive local anaesthetic infiltration i.e preincisional local anaesthesia, be given as standard practice in patients undergoing laparoscopic gall bladder procedures.

\section{References}

1. Serra AS, Roig MP, Lledo JB, et al. The Learning Curve in Ambulatory Laparoscopic Cholecystectomy. Surg Laparosc Endosc Percutan Tech 2002; 12(5):320-324.

2. McMahon AJ, Russell IT, Baxter JN, et al. Laparoscopic versus minilaparotomy cholecystectomy: a randomised trial. Lancet 1994; 343:135-138.

3. McGinn FP, Miles AJG, Uglow M, et al. Randomized trial of laparoscopic cholecystectomy and minicholecystectomy. Br J Surg 1995; 82:1374-1377.

4. Bisgaard T. Analgesic Treatment after Laparoscopic Cholecystectomy. Anesthesiology 2006; 104:835-846.

5. Vijayan R, Delilkan AE. First year's experience with an acute pain service--University Hospital Kuala Lumpur. Med J Malaysia 1994; 49(4):385-400.

6. Vijayan R, Tay KH, Tan LB, et al. Survey of postoperative pain in University Hospital Kuala Lumpur. Singapore Med J 1994; 35(5):502-504.

7. Gabriel S. Laparoscopic cholecystectomy. Can Oper Room Nurs J 1990; 8(5):19-24.

8. Zemon H, Ponsky TA. Acute cholecystitis. In Current Surgical Therapy. 9th ed. Philadelphia: Cameron JL. ed. Mosby Elsevier; 2008: 408-412.

9. Livingston EH, Rege RV. A nationwide study of conversion from laparoscopic to open cholecystectomy. Am J Surg 2004; 188(3):205-211.

10. Bakos $\mathrm{E}$, Bakos $\mathrm{M}$, Dubai $\mathrm{M}$, et al. Conversions in laparoscopic cholecystectomy. Brastil Lek Listy 2008; 109(7):317-319.

11. Zailinawati $\mathrm{AH}$, Teng $\mathrm{CL}$, Kamil $\mathrm{MA}$, et al. Pain morbidity in primary care - preliminary observations 
from two different primary care settings. Med J Malaysia 2006; 61(2):162-167.

12. Cruccu G, Anand P, Attal N, et al. EFNS guidelines on neuropathic pain assessment. European Journal of Neurology 2004; 11:153-162.

13. Ke RW, Portera SG, Bagous W, et al. A Randomized, Double-blinded Trial of Preemptive Analgesia in Laparoscopy. Obstet Gynecol 1998; 92:972-975.

14. Yeh CC, Jao SW, Huh BK, et al. Preincisional Dextromethorphan Combined with Thoracic Epidural Anesthesia and Analgesia Improves Postoperative Pain and Bowel Function in Patients Undergoing Colonic Surgery. Anesth Analg 2005; 100:1384-1389.

15. White PF. The Role of Non-Opioid Analgesic Techniques in the management of Pain After Ambulatory Surgery. Anesth Analg 2002; 94:577-585.

16. White PF. The Changing Role of Non-Opioid Analgesic Techniques in the Management of Postoperative Pain. Anesth Analg 2005; 101:S2-S55.

17. Bisgaard T, Klarskov B, Kristiansen VB, et al. Multi-Regional Local Anesthetic Infiltration During Laparoscopic Cholecystectomy in Patients Receiving Prophylactic Multi-Modal Analgesia: A Randomized, Double-Blinded, Placebo-Controlled Study. Anesth Analg 1999; 89:1017-1024.

18. Downs SH, Black NA, Devlin HB, et al. Systematic review of the effectiveness and safety of laparoscopic cholecystectomy. Ann R Coll Surg Engl 1996; 78:241323.

19. Wills VL, Hunt DR. Pain after laparoscopic cholecystectomy. Br J Surg 2000; 87(3):273-284.

20. Bisgaard T, Klarskov B, Rosenberg J, et al. Characteristics and prediction of early pain after laparoscopic cholecystectomy. Pain 2001; 90:261-269.

21. Woolf CJ. Central sensitization: Uncovering the relation between pain and plasticity. Anesthesiology 2007; 106:864-867.

22. Gottschalk A, Smith DS. New Concepts in Acute Pain Therapy: Preemptive Analgesia. Am Fam Physician 2001; 63:1979-1984.

23. Chiang CY, Li Z, Dostrovsky JO, et al. Glutamine uptake contributes to central sensitization in the medullary dorsal horn. NeuroReport 2008; 19:1151-1154.

24. Hasaniya NW, Zayed FF, Faiz H, et al. Preinsertion local anesthesia at the trocar site improves perioperative pain and decreases costs of laparoscopic cholecystectomy. Surg Endosc 2001; 15(9):962-964.

25. Power C, Dowdall JF, Khan F, et al. Preemptive analgesia by local anaesthetic infiltration: a prospective doubleblind randomized placebo-controlled trial. Br J Surg 2000; 87(Suppl 1):34.

26. Dath D, Park AE. Randomized, controlled trial of bupivacaine injection to decrease pain after laparoscopic cholecystectomy. Can J Surg 1999; 42(4):284-288.

27. Uzunkoy A, Coskun A, Faruk-Akinci O. The application of local analgesia before and after surgery in laparoscopic cholecystectomy. Dolor 1999; 14(4):287289.

28. Uzunkoy A, Coskun A, Faruk-Akinci O. The value of preemptive analgesia in the treatment of postoperative pain after laparoscopic cholecystectomy. European surgical research 2001; 33(1):39-41.

29. Lee IO, Kim SH, Kong MH, et al. Pain after laparoscopic cholecystectomy: the effect and timing of incisional and intraperitoneal bupivacaine. Can J Anaesth 2001; 48(6):545-550.

30. Sarac AM, Aktan AO, Baykan N, et al. The Effect and Timing of Local Anesthesia in Laparoscopic Cholecystectomy. Surg Laparosc Endosc 1996; 6(5):362-366.

31. Maestroni U, Sortini D, Devito C, et al. A new method of preemptive analgesia in laparoscopic cholecystectomy. Surg Endosc 2002; 16:1336-1340.

32. Chok KS, Yuen WK, Lau H, et al. Prospective randomized trial on low-pressure versus standard-pressure pneumoperitoneum in outpatient laparoscopic cholecystectomy. Surg Laparosc Endosc Percutan Tech 2006; 16(6):383-386.

33. Sarli L, Costi R, Sansebastiano G, et al. Prospective randomized trial of low-pressure pneumoperitoneum for reduction of shoulder-tip pain following laparoscopy. Br J Surg 2000; 87(9):1161-1165.

34. Rawal N. Acute pain services revisited: good from far, far from good? Reg Anesth Pain Med 2002; 27:117121.

35. Bardiau FM, Taviaux NF, Boogaerts JG, et al. An intervention study to enhance postoperative pain management. Anesth Analg 2003; 96:176-185.

36. Wu CT, Yu JC, Yeh CC, et al. Preincisional Dextromethorphan Treatment Decreases Postoperative Pain and Opioid Requirement After Laparoscopic Cholecystectomy. Anesth Analg 1999; 88:1331-1334.

37. Michaloliakou C, Chung F, Sharma S. Preoperative Multimodal Analgesia Facilitates Recovery After Ambulatory Laparoscopic Cholecystectomy. Anesth Analg 1996; 82:44-51.

38. Pasqualucci A, DeAngelis V, Contardo R, et al. Preemptive Analgesia: Intraperitoneal Local Anesthetic in Laparoscopic Cholecystectomy: A Randomized, Double-blind, Placebo-controlled Study. Anesthesiology 1996; 85(1):11-20.

39. Labaille T, Mazoit JX, Paqueron X, et al. The Clinical Efficacy and Pharmacokinetics of Intraperitoneal Ropivacaine for Laparoscopic Cholecystectomy. Anesth Analg 2002; 94:100-105.

40. Barczynski M, Konturek A, Herman RM. Superiority of preemptive analgesia with intraperitoneal instillation of bupivacaine before rather than after the creation of pneumoperitoneum for laparoscopic cholecystectomy: a randomized, double-blind, placebo-controlled study. Surg Endosc 2006, 20(7):1088-1093. 